\title{
The use of extended criteria donors decreases one-year survival in high-risk lung recipients: A review of the United Network of Organ Sharing Database
}

\author{
Matthew J. Mulligan, BA, ${ }^{a}$ Pablo G. Sanchez, MD, PhD, ${ }^{\mathrm{b}}$ Charles F. Evans, MD, ${ }^{\mathrm{b}}$ Yan Wang, BM, DrPH, \\ Zachary N. Kon, MD, ${ }^{\mathrm{b}}$ Keshava Rajagopal, MD, PhD, ${ }^{\mathrm{b}}$ Aldo T. Iacono, MD, ${ }^{\mathrm{d}}$ James S. Gammie, MD, \\ Bartley P. Griffith, MD, ${ }^{b}$ and Si M. Pham, $\mathrm{MD}^{\mathrm{b}}$
}

\section{ABSTRACT}

Objective: The study objective was to investigate the impact of matching donor quality to recipient severity on survival after lung transplant.

Methods: By using the Organ Procurement and Transplantation Network/United Network for Organ Sharing dataset, we analyzed lung transplant recipients from May 4, 2005, to December 31, 2012. By using adjusted Cox regressions, we identified extended criteria donors as those who had 1 or more of the following: age 65 years or more, smoking history of 20 pack-years or more, diabetes mellitus, or African-American race. All other donors were considered standard donors. Recipients were categorized by lung allocation score: lung allocation score less than 70 and lung allocation score 70 or greater. Our primary outcome was 1-year survival after lung transplantation.

Results: Of the 10,995 lung recipients, 3792 (34\%) received extended criteria donor organs. Extended criteria donors were associated with an increased hazard of death (hazard ratio [HR], 1.41; 95\% confidence interval [CI], 1.26-1.56; $P<.001)$. One-year survival was $87 \%$ and $82 \%(P<.001)$ for recipients with a lung allocation score less than 70 and $80 \%$ and $72 \%(P=.017)$ for recipients with a lung allocation score 70 or greater who received standard donor and extended criteria donor organs, respectively. In Cox regression models, the hazard of death was increased for recipients with a lung allocation score less than $70+$ extended criteria donor (HR, 1.42; 95\% CI, 1.27-1.60; $P<.001$ ), recipients with a lung allocation score 70 or greater + standard donor (HR, 1.37; 95\% CI, $1.10-1.71 ; P=.005)$, and was the highest for recipients with a lung allocation score 70 or greater + extended criteria donor (HR, 1.81; 95\% CI, 1.40-2.33; $P<.001)$ compared with recipients with a lung allocation score less than $70+$ standard donor.

Conclusions: Extended criteria donors are associated with reduced 1-year survival, and recipients with a lung allocation score 70 or greater who receive extended criteria donor organs have the lowest survival. (J Thorac Cardiovasc Surg 2016;152:891-8)

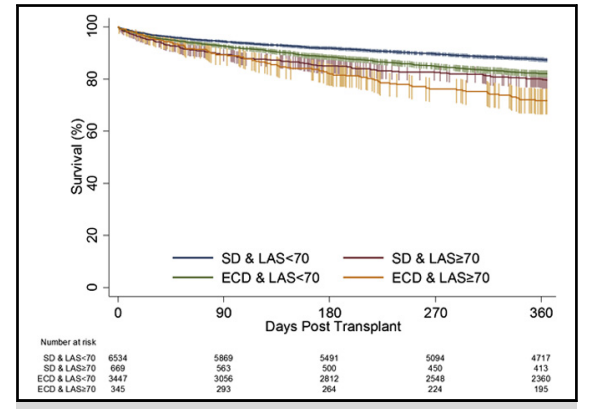

Survival by donor quality and recipient severity with a $95 \% \mathrm{Cl}$.

\section{Central Message}

Matching donor quality to recipient severity is critical to achieve optimal outcomes in lung transplantation.

\section{Perspective}

Lung transplantation is limited by donor shortage. The use of donors who do not meet all ideal donor criteria increases donor availability but potentially decreases survival By using the OPTN/UNOS dataset, we showed that the use of ECDs is associated with reduced 1-year survival and that survival is the lowest in lung recipients with a LAS 70 or greater who receive an ECD organ.

See Editorial Commentary page 899

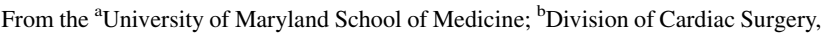
Department of Surgery, ${ }^{c}$ Department of Pediatrics, and ${ }^{\mathrm{d}} \mathrm{R}$ Adams Cowley Shock Trauma Center, University of Maryland School of Medicine, Baltimore, Md. Read at the 95th Annual Meeting of The American Association for Thoracic Surgery, Seattle, Washington, April 25-29, 2015.

Received for publication May 18, 2015; revisions received March 30, 2016; accepted for publication March 31, 2016; available ahead of print May 24, 2016.

Address for reprints: Si M. Pham, MD, Division of Cardiac Surgery, University of Maryland School of Medicine, 110 S Paca St, 7th Floor, Baltimore, MD 21201 (E-mail: spham@smail.umaryland.edu).

$0022-5223 / \$ 36.00$

Copyright (c) 2016 by The American Association for Thoracic Surgery http://dx.doi.org/10.1016/j.jtcvs.2016.03.096
}

Lung transplantation remains the standard treatment for end-stage pulmonary disease. However, it is currently

Scanning this QR code will take you to supplemental tables and a video of the meeting presentation for this article.

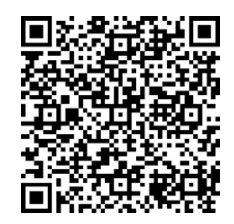




$$
\begin{aligned}
& \text { Abbreviations and Acronyms } \\
& \begin{aligned}
& \text { BMI }=\text { body mass index } \\
& \text { CI }=\text { confidence interval } \\
& \text { CMV }=\text { cytomegalovirus } \\
& \text { ECD }=\text { extended criteria donor } \\
& \text { HR }=\text { hazard ratio } \\
& \text { LAS }=\text { lung allocation score } \\
& \text { OPTN }=\text { Organ Procurement and Transplantation } \text { Network } \\
& \text { SD } \text { standard donor } \\
& \text { UNOS }=\text { United Network for Organ Sharing }
\end{aligned}
\end{aligned}
$$

limited by a severe shortage of usable donors. In 2013, there were 8268 brain-dead donors in the United States, but only 1922 lung transplants (Organ Procurement and Transplantation Network [OPTN] data as of February 20, 2015; http:// optn.transplant.hrsa.gov). The ideal donor criteria, which includes $\mathrm{ABO}$ compatibility, age less than 55 years, clear chest radiograph, smoking history of 20 pack-years or less, arterial oxygen tension $300 \mathrm{~mm} \mathrm{Hg}$ or greater on $100 \%$ oxygen with $5 \mathrm{~cm} \mathrm{H}_{2} \mathrm{O}$ positive end-expiratory pressure, absence of significant chest trauma, no aspiration/ sepsis, no prior cardiac/pulmonary operation, no organisms on donor gram stain if prolonged intubation, no purulent secretions on bronchoscopy, and adequate size match, were drafted with the intention of selecting lungs that could tolerate the effects of ischemia-reperfusion while providing good outcomes. ${ }^{1}$ The use of donors who deviate from these ideal criteria has allowed centers to increase the number of transplants without an apparent detriment on outcomes. ${ }^{2-5}$ A recent study of the OPTN/United Network for Organ Sharing (UNOS) database revealed that $56 \%$ of the lung donors used for transplants had at least 1 variance from the ideal donor criteria. ${ }^{6}$ However, to date there is a paucity of data on the impact of matching donor quality to recipient severity in lung transplant outcomes.

The goals of this study were to use the OPTN/UNOS database to identify donor factors that were associated with reduced post-transplant 1-year survival, to use these identified factors to define extended criteria donors (ECDs), and to evaluate 1-year survival of low- and high-risk lung recipients who received standard donor (SD) or ECD lungs. Our hypothesis is that transplanting ECD lungs into high-risk recipients would be associated with worse survival.

\section{MATERIALS AND METHODS}

We performed a retrospective analysis of 10,995 lung transplant recipients in the OPTN/UNOS Transplant Registry from May 4, 2005, to December 31, 2012. We excluded recipients aged less than 18 years, recipients of lungs from donation after circulatory determination of dead donors, retransplants, recipients on extracorporeal membrane oxygenation, recipients who received lobar transplants, and recipients with multiorgan transplants. The primary outcome was 1-year survival after lung transplantation.

\section{Extended Criteria Donors}

A series of univariate Cox hazard regressions on 1-year survival were performed on pertinent donor criteria available in the OPTN/UNOS database, including age categorized by age less than 55 years, age 55 years or more and less than 65 years, and age 65 years or more; arterial oxygen tension $300 \mathrm{~mm} \mathrm{Hg}$ or less; history of smoking 20 pack-years or more; abnormal chest $\mathrm{x}$-ray; purulent secretions on bronchoscopy; sex; race categorized by Caucasian, African-American, and other; diabetes mellitus; mechanism of death categorized by stroke, blunt trauma, gunshot, asphyxiation, and other; body mass index (BMI); coronary artery disease; hypertension; and $\mathrm{ABO}$ blood group categorized by $\mathrm{A}, \mathrm{B}, \mathrm{AB}$, and $\mathrm{O}$ (Table $\mathrm{E} 1$ ). Donor factors found to be significantly associated with reduced survival in the univariate analysis were run in a stepwise Cox hazard regression model adjusted for recipient variables known to influence transplant survival (Table E2). We found that donor age 65 years or more, history of smoking 20 pack-years or more, diabetes, and African-American race were all independent risk factors for death in 1 year after transplant. Any donor who had any 1 of these identified criteria was considered an ECD. Donors who did not meet any of the criteria were considered SDs. There were missing values for identified ECD factors: history of smoking 20 pack-years or more $(\mathrm{n}=96)$ and diabetes $(\mathrm{n}=32)$. The percentage of missing values for at least $1 \mathrm{ECD}$ factor is $1 \%$.

\section{Recipient Severity}

Recipients were categorized according to their lung allocation score (LAS): LAS less than 70 or LAS 70 or greater. We found that only recipients with LAS 70 or greater were associated with decreased survival in 1 year, which is consistent with previous work demonstrating that a LAS 70 or greater has an increased hazard of post-transplant death.

\section{Pairing of Donor Quality With Recipient Severity}

A 4-category variable was created to indicate the overall risk status of matching donor quality and recipient severity: SD and LAS less than 70, ECD and LAS less than 70, SD and LAS 70 or greater, and ECD and LAS 70 or greater.

\section{Covariates}

Covariates were variables significantly associated with reduced transplant survival and included cytomegalovirus (CMV) mismatch, mechanical ventilation, BMI, creatinine, total bilirubin, ischemic time, single lung transplant, sex, age, and diagnosis categorized by idiopathic pulmonary fibrosis, chronic obstructive pulmonary disease, cystic fibrosis, pulmonary hypertension $\alpha 1$-antitrypsin deficiency, and other diagnoses. In models using LAS as a marker for recipient severity, we controlled for variables in the LAS that were independent predictors of survival, which included age, diagnosis, creatinine, total bilirubin, and mechanical ventilation, and transplant variables including CMV mismatch, single lung, and ischemic time. There were missing values for the covariates: BMI $(n=1)$, creatinine $(n=64)$, total bilirubin $(n=299)$, ischemic time $(\mathrm{n}=576)$, CMV mismatch $(\mathrm{n}=645)$, and diagnosis $(\mathrm{n}=1)$. The percentage of missing values for at least 1 covariate is $12 \%$.

\section{Statistical Analysis}

Continuous variables were expressed as mean \pm standard deviation or median and interquartile range, and categoric variables were expressed as counts and percentages. Student $t$ tests were used to test continuous variables with normal distributions, and the Mann-Whitney $U$ test was used for non-normal continuous variables. Categoric variables were tested using the chi-square and Fisher exact tests. Survival was evaluated using Kaplan-Meier methods and compared with log-rank tests. Kaplan-Meier survival is presented as percentage survival \pm standard error. Cox proportional hazard models were performed to assess the recipient/donor risk status in relation to time to death before and after adjusting for 
covariates (Tables E3-E5), and the adjusted models are presented in the text. Hazard ratios (HRs) and 95\% confidence intervals (CIs) of death were estimated on the basis of the Cox proportional hazard model. An interaction term was created between ECDs and LAS 70 or greater, and the significance of the interaction was evaluated using the Wald test. All statistical analysis was performed using Stata 14.1 software (StataCorp LP, College Station, Tex).

\section{RESULTS}

\section{Characteristics of Extended Criteria Donors and Standard Donors}

Of the 10,995 identified recipients of lung transplantation, 34\% $(\mathrm{n}=3792)$ received a transplant from an ECD. There were numerous differences in baseline donor characteristics of ECDs and SDs (Table 1). As expected, there were significant differences between ECDs and SDs in all donor factors used to define ECDs: age, race, smoking history 20 pack-years or more, and diabetes. There were also significant differences in the mechanism of donor death between ECDs and SDs $(P<.001)$. Because of age differences between the groups, a higher percentage of ECDs died of a stroke (46\% ECD vs 34\% SD) and less from blunt trauma ( $15 \%$ ECD vs $31 \%$ SD). The majority of donors in both groups were CMV positive $(68 \% \mathrm{ECD}$ vs $60 \% \mathrm{SD}$; $P<.001$ ), but there were more ECDs who were CMV positive than SDs. There were also significant differences in ABO group for ECDs compared with SDs $(P<.001)$. Fewer ECDs had type A blood ( $31 \%$ ECD vs $38 \%$ SD), but more had type B (14\% ECD vs $9 \%$ SD) and type O blood (53\% ECD vs $50 \%$ SD).

\section{Characteristics of Recipients With a Lung Allocation Score Less Than 70 and a Lung Allocation Score 70 or Greater by Donor Type}

The baseline characteristics of lung recipients stratified by LAS $(<70$ or $\geq 70)$ are depicted in Table 2. ECDs were used in $35 \%(n=3447)$ of recipients with a LAS less than 70 and $34 \%(n=345)$ of recipients with a LAS 70 or greater $(P=.744)$. Recipients with a LAS less than 70 who received a transplant from an ECD were older compared with those who received a transplant from an SD (mean age, 55.4 years ECD vs 54.5 years SD; $P<.001)$. A greater percentage of recipients who received a transplant from an ECD were CMV mismatched. There were more single lung transplants in recipients with a LAS less than 70 who received ECD lungs than those who received SD lungs ( $37 \%$ vs $35 \% ; P=.016)$. There were also differences in ischemic time categories for recipients with a LAS less than $70(P=.036)$. There were fewer recipients with a LAS less than 70 who received ECD lungs compared with SDs who had an ischemic time greater than 4 hours but less than 6 (46\% ECD vs $49 \%$ SD) and more with an ischemic time greater than 6 hours but less than 8 ( $22 \%$ ECD vs $20 \% \mathrm{SD})$.
TABLE 1. Characteristics of extended criteria donors and standard donors

\begin{tabular}{|c|c|c|c|}
\hline & $\begin{array}{c}\text { SD } \\
(N=7203)\end{array}$ & $\begin{array}{c}\text { ECD } \\
(\mathbf{N}=3792)\end{array}$ & $\begin{array}{c}P \\
\text { value }\end{array}$ \\
\hline \multicolumn{4}{|l|}{ Age, y $(\mathrm{n}=10,995)$} \\
\hline$<18$ & $838(12)$ & $255(7)$ & \\
\hline $18-34$ & $3560(49)$ & $1358(36)$ & \\
\hline $35-54$ & $2201(31)$ & $1674(44)$ & \\
\hline $55-64$ & $604(8)$ & $387(10)$ & \\
\hline$>65$ & $0(0)$ & $118(3)$ & $<.001$ \\
\hline Female $(\mathrm{n}=10,995)$ & $2835(40)$ & $1571(41)$ & .035 \\
\hline \multicolumn{4}{|l|}{ Race $(\mathrm{n}=10,995)$} \\
\hline Caucasian & $5421(75)$ & $1383(36)$ & \\
\hline African-American & - & $2124(56)$ & \\
\hline Other & $1782(26)$ & $285(8)$ & $<.001$ \\
\hline \multicolumn{4}{|c|}{ Mechanism of death $(\mathrm{n}=10,994)$} \\
\hline Stroke & $2436(34)$ & $1746(46)$ & \\
\hline Blunt trauma & $2264(31)$ & $561(15)$ & \\
\hline Gunshot & $1279(18)$ & $902(24)$ & \\
\hline Asphyxiation & $206(3)$ & $73(2)$ & \\
\hline Other & $1017(14)$ & $510(13)$ & $<.001$ \\
\hline Median $\mathrm{PaO}_{2}(\mathrm{n}=10,901)$ & $421(241-491)$ & $425(260-500)$ & .032 \\
\hline $\begin{array}{l}\text { History of } \geq 20 \text { pack-y } \\
\quad \text { cigarette use }(n=10,899)\end{array}$ & $0(0)$ & $1291(34)$ & $<.001$ \\
\hline $\begin{array}{l}\text { X-ray abnormalities } \\
\quad(\mathrm{n}=10,955)\end{array}$ & $3337(47)$ & $1602(42)$ & $<.001$ \\
\hline $\begin{array}{l}\text { Purulent secretions on } \\
\text { bronchoscopy }(\mathrm{n}=9914)\end{array}$ & $827(13)$ & $465(14)$ & .196 \\
\hline Diabetes $(n=10,963)$ & $0(0)$ & $720(19)$ & $<.001$ \\
\hline \multicolumn{4}{|l|}{ CMV status $(\mathrm{n}=10,977)$} \\
\hline CMV positive & $4296(60)$ & $2590(68)$ & \\
\hline CMV Indeterminate & $15(0)$ & $9(0)$ & $<.001$ \\
\hline \multicolumn{4}{|l|}{$\mathrm{ABO}$ group $(\mathrm{n}=10,995)$} \\
\hline A & $2766(38)$ & $1170(31)$ & \\
\hline $\mathrm{AB}$ & $151(2)$ & $87(2)$ & \\
\hline B & $668(9)$ & $528(14)$ & \\
\hline $\mathrm{O}$ & $3618(50)$ & $2007(53)$ & $<.001$ \\
\hline
\end{tabular}

Continuous variables are expressed as median (interquartile range), and categoric variables are expressed as number (\%). $S D$, Standard donor; $E C D$, extended criteria donor; $\mathrm{PaO}_{2}$, arterial oxygen tension (mm Hg); $\mathrm{CMV}$, cytomegalovirus.

\section{Comparative Outcomes of Extended Criteria Donors Versus Standard Donors by Recipient Lung Allocation Score}

There was no difference in median waitlist time for recipients receiving $\mathrm{ECD}$ or $\mathrm{SD}$ organs for recipients with a LAS less than 70 (75 ECD vs 83 SD days; $P=.098$ ) and recipients with a LAS 70 or greater (22 ECD vs 23 SD days; $P=.926$ ) (Table 3). Median length of stay was longer for recipients receiving ECD organs for recipients with a LAS less than 70 (15 days ECD vs 14 days SD; $P<.001)$ and recipients with a LAS 70 or greater ( 25 days ECD vs 20 days SD; $P<.001$ ). Recipients with a LAS less than 70 had an increased incidence of postoperative dialysis when receiving an ECD transplant compared with an SD transplant (LAS <70: 6\% ECD vs $4 \% \mathrm{SD} ; P<.001)$. There was no difference in the rates of 
TABLE 2. Comparison of baseline characteristics for recipients with a lung allocation score less than 70 and a lung allocation score 70 or more by donor type

\begin{tabular}{|c|c|c|c|c|c|c|}
\hline & \multicolumn{3}{|c|}{ LAS $<70$} & \multicolumn{3}{|c|}{$\mathbf{L A S} \geq \mathbf{7 0}$} \\
\hline & SD $(N=6534)$ & $\operatorname{ECD}(\mathbf{N}=3447)$ & $P$ value & $\operatorname{SD}(N=669)$ & $\operatorname{ECD}(N=345)$ & $P$ value \\
\hline Mean age, $y(n=10,995)$ & $54.5 \pm 13.1$ & $55.4 \pm 12.5$ & $<.001$ & $54.6 \pm 13.7$ & $53.5 \pm 13.5$ & .223 \\
\hline Female $(\mathrm{n}=10,995)$ & $2719(42)$ & $1418(41)$ & .646 & $241(36)$ & $133(39)$ & .429 \\
\hline \multicolumn{7}{|l|}{ Race $(\mathrm{n}=10,995)$} \\
\hline Caucasian & $5561(85)$ & $2893(84)$ & & $525(78)$ & $281(81)$ & \\
\hline African-American & $498(8)$ & $347(10)$ & & $61(9)$ & $27(8)$ & \\
\hline Other & $475(7)$ & $207(6)$ & $<.001$ & $83(12)$ & $37(11)$ & .539 \\
\hline \multicolumn{7}{|l|}{ Diagnosis $(n=10,994)$} \\
\hline COPD & $2009(31)$ & $1089(32)$ & .388 & $27(4)$ & $9(3)$ & .245 \\
\hline IPF & $2095(32)$ & $1105(32)$ & .991 & $404(60)$ & $200(58)$ & .457 \\
\hline Cystic fibrosis & $836(13)$ & $383(11)$ & .014 & $74(11)$ & $44(13)$ & .426 \\
\hline Pulmonary hypertension & 207 (3) & $107(3)$ & .861 & $7(1)$ & $4(1)$ & 1.000 \\
\hline$\alpha 1$-antitrypsin & $186(3)$ & $113(3)$ & .230 & $2(0)$ & 0 & .551 \\
\hline Other & $1200(18)$ & $650(19)$ & .550 & $155(23)$ & $88(26)$ & .409 \\
\hline Median LAS at transplant $(\mathrm{n}=10,995)$ & $38(34-45)$ & $38(34-44)$ & .037 & $87(78-92)$ & $87(78-92)$ & .830 \\
\hline \multicolumn{7}{|l|}{ Comorbidities } \\
\hline Diabetes $(\mathrm{n}=10,991)$ & $1093(17)$ & $572(17)$ & .854 & $173(26)$ & $87(25)$ & .824 \\
\hline Total bilirubin, $\mathrm{mg} / \mathrm{dL}(\mathrm{n}=10,696)$ & $0.64 \pm 0.89$ & $0.65 \pm 1.06$ & .601 & $0.73 \pm 1.16$ & $0.97 \pm 3.8$ & .140 \\
\hline Creatinine, $\mathrm{mg} / \mathrm{dL}(\mathrm{n}=10,931)$ & $0.86 \pm 0.43$ & $0.87 \pm 0.40$ & .467 & $0.81 \pm 0.35$ & $0.82 \pm 0.44$ & .685 \\
\hline $\operatorname{BMI}(\mathrm{n}=10,994)$ & $24.9 \pm 4.6$ & $25.2 \pm 4.9$ & .002 & $25.6 \pm 4.9$ & $25.6 \pm 5.0$ & .813 \\
\hline Mechanical ventilation $(\mathrm{n}=10,995)$ & $182(3)$ & $122(4)$ & .037 & $160(24)$ & $95(28)$ & .208 \\
\hline CMV mismatch $(\mathrm{n}=10,350)$ & $1486(24)$ & $892(28)$ & $<.001$ & $147(23)$ & $100(31)$ & .007 \\
\hline Single lung transplant $(\mathrm{n}=10,995)$ & $2257(35)$ & $1274(37)$ & .016 & $168(25)$ & $89(26)$ & .812 \\
\hline \multicolumn{7}{|l|}{ Ischemic time $(\mathrm{h})(\mathrm{n}=10,419)$} \\
\hline$<4$ & $1652(27)$ & $874(27)$ & & $139(22)$ & $56(17)$ & \\
\hline$\geq 4$ and $<6$ & $2997(49)$ & $1513(46)$ & & $298(46)$ & $171(52)$ & \\
\hline$\geq 6$ and $<8$ & $1238(20)$ & $705(22)$ & & $169(26)$ & $78(23)$ & \\
\hline$\geq 8$ & $285(5)$ & $18,262(6)$ & .036 & $35(5)$ & $17(8)$ & .077 \\
\hline
\end{tabular}

Continuous variables are expressed as median (interquartile range) or mean \pm standard deviation, and categoric variables are expressed as number (\%). LAS, Lung allocation score; $S D$, standard donor; $E C D$, extended criteria donor; $C O P D$, chronic obstructive pulmonary disease; $I P F$, idiopathic pulmonary fibrosis; $B M I$, body mass index; $C M V$, cytomegalovirus.

postoperative dialysis for recipients with a LAS 70 or greater by donor quality. There were no differences in acute rejection, postoperative stroke, and airway dehiscence between donor groups in recipients with a LAS less than 70 and a LAS 70 or greater.

\section{One-Year Survival}

ECDs were associated with a significant reduction in 1-year survival (HR, 1.41; 95\% CI, 1.26-1.56; $P<.001$ ) (Table 4). The individual donor factors used to define ECDs were all independently associated with an increased hazard of death within 1 year: donor age 65 years or more (HR, 2.14; 95\% CI, 1.50-3.07; $P<.001$ ), a history of cigarette use for 20 pack-years or more (HR, 1.29; 95\% CI, 1.11-1.51; $P=.001$ ), diabetes mellitus (HR, 1.29; 95\% CI, 1.07-1.57; $P=.009)$, and African-American race (HR, 1.34; 95\% $\mathrm{CI}, 1.18-1.52 ; P<.001)$. Meeting 1 $(\mathrm{n}=3360)$ or 2 or more $(\mathrm{n}=432)$ of the donor factors used to define ECDs was associated with increasing hazard of death compared with SDs (HR, 1.35; 95\% CI, 1.20-1.51;
$P<.001 ;$ HR, 1.86; 95\% CI, 1.49-2.32; $P<.001$, respectively) (Table 5).

Recipients who received transplants from ECDs were associated with reduced 1-year survival compared with those who received transplants from SDs: $82.0 \%$ versus $87.3 \%(P<.001)$ for recipients with LAS less than 70 and $71.7 \%$ versus $79.6 \%(P=.017)$ for recipients with a LAS 70 or greater (Figure 1). In adjusted Cox regression models, the hazard of death was increased for recipients with a LAS less than 70 who received an ECD lung (HR, $1.42,95 \%$ CI, $1.27-1.60 ; P<.001)$ and recipients with a LAS 70 or greater who received an SD lung (HR, 1.37, $95 \% \mathrm{CI}, 1.10-1.71 ; P=.005$ ), and was the highest for recipients with a LAS 70 or greater who received an ECD lung (HR, 1.81, 95\% CI, 1.40-2.33; $P<.001$ ) compared with recipients with a LAS less than 70 who received an SD lung (Table 6). There was no significant statistical interaction between recipients with a LAS 70 or greater and ECDs $(P=.643$ for the interaction term $)$ in relation to the hazard of death. 
TABLE 3. Comparison of lung transplant outcomes for recipients with a lung allocation score less than 70 and a lung allocation score 70 or more by donor type

\begin{tabular}{|c|c|c|c|c|c|c|}
\hline & \multicolumn{3}{|c|}{ LAS $<70$} & \multicolumn{3}{|c|}{ LAS $\geq \mathbf{7 0}$} \\
\hline & SD $(N=6534)$ & ECD $(N=3447)$ & $P$ value & SD $(N=669)$ & $\operatorname{ECD}(\mathbf{N}=345)$ & $P$ value \\
\hline Median waitlist time, $\mathrm{d}(\mathrm{n}=10,995)$ & $83(25-246)$ & $75(24-234)$ & .098 & $23(7-88)$ & $22(6-102)$ & .936 \\
\hline \multicolumn{7}{|l|}{ Predischarge complications } \\
\hline Acute rejection $(\mathrm{n}=10,964)$ & $546(8)$ & $324(9)$ & .081 & $65(10)$ & $47(14)$ & .057 \\
\hline Airway dehiscence $(\mathrm{n}=10,963)$ & $87(1)$ & $62(2)$ & .068 & $7(1)$ & $7(2)$ & .201 \\
\hline Dialysis $(\mathrm{n}=10,964)$ & $275(4)$ & $201(6)$ & $<.001$ & $62(9)$ & $42(12)$ & .142 \\
\hline Stroke $(\mathrm{n}=10,964)$ & $115(2)$ & $65(2)$ & .657 & $18(3)$ & $12(4)$ & .476 \\
\hline Median length of stay $(d)(n=10,771)$ & $14(10-22)$ & $15(11-27)$ & $<.001$ & $20(13-35)$ & $25(16-43)$ & $<.001$ \\
\hline 1 -y transplant survival $(\mathrm{n}=10,995)$ & $87.3 \pm 0.4$ & $82.0 \pm 0.7$ & $<.001$ & $79.6 \pm 1.6$ & $71.7 \pm 2.6$ & .017 \\
\hline
\end{tabular}

Continuous variables are expressed as median (interquartile range), survival data are expressed as percentage survival \pm standard error, and categoric variables are expressed as number $(\%)$. LAS, Lung allocation score; $S D$, standard donor; $E C D$, extended criteria donor.

\section{DISCUSSION}

In our analysis of the OPTN/UNOS database from May 4, 2005, after the implementation of the LAS, to December 31, 2012, using adjusted Cox regressions, we identified 4 donor extended criteria that were independently associated with poor survival outcome: age 65 years or more, a smoking history of 20 pack-years or more, diabetes, and African-American donors. We also demonstrated that ECDs were associated with reduced 1-year survival and that recipients with a LAS 70 or greater who received ECD organs had the lowest survival. Because transplant outcomes are closely monitored by various governmental and insurance agencies, results from our analysis will provide useful information for lung transplant teams to make appropriate decisions for their patients and their transplant center.

TABLE 4. Adjusted Cox regressions of donor factors and extended criteria donors on one-year survival

\begin{tabular}{lccr}
\hline & Adjusted HR & 95\% CI & $P$ value \\
\hline Donor factor model $(\mathrm{n}=9563)$ & & & \\
$\quad$ Age $\geq 65$ y & 2.14 & $1.50-3.07$ & $<.001$ \\
History smoking $\geq 20$ Pack-y & 1.29 & $1.11-1.51$ & .001 \\
Diabetes & 1.29 & $1.07-1.57$ & .009 \\
$\quad$ African American & 1.34 & $1.18-1.52$ & $<.001$ \\
Combined model $(\mathrm{n}=9658)$ & & & \\
$\quad$ ECD & 1.41 & $1.26-1.56$ & $<.001$ \\
\hline
\end{tabular}

The donor factor model presents the results of a stepwise regression to identify donor factors that were independently associated with a reduction in 1-y survival. In the combined donor model, ECDs were defined as having at least 1 of the following: age $\geq 65$ y, history of smoking $\geq 20$ pack-y, diabetes, or African-American race. All Cox regression models controlled for recipient variables, which included CMV mismatch, mechanical ventilation, BMI, creatinine, total bilirubin, ischemic time categorized by $<4, \geq 4$, and $<6, \geq 6$ and $<8$, and $\geq 8$, single lung transplant, sex, age, and diagnosis categorized by idiopathic pulmonary fibrosis (IPF), chronic obstructive pulmonary disease (COPD), cystic fibrosis, pulmonary hypertension $\alpha 1$-antitrypsin deficiency, and other diagnoses. There were missing values in donor factors and covariates in the donor factor model and covariates in the combined model. The percentage of missing values for at least 1 variable in the donor factor model is $13 \%$. The percentage of missing values for at least 1 covariate in the combined model is $12 \%$. $H R$, Hazard ratio; $C I$, confidence interval; $E C D$, extended criteria donor.
In the current literature, there is a paucity of data to guide the decision of matching donor quality to recipient severity. In a retrospective analysis of 123 lung transplants, the Toronto group demonstrated that nonguideline recipients had acceptable early mortality except when they received ECD lungs. ${ }^{8}$ Conversely, Moreno and colleagues, ${ }^{9}$ in a single-center analysis of 365 lung transplants with SDs and ECDs, concluded that only recipient characteristics adversely affected survival. ${ }^{9}$ However, in these studies the definition of ECDs as those who had any variance from the ideal donor criteria do not accurately identify ECDs, because some of these variances have not been shown to be associated with poor outcome after lung transplantation. In our current study, we used regression analysis to identify donor risk factors that were independently associated with post-transplant survival and used these risk factors to define ECDs. We also matched donor quality to LAS, a welldefined recipient's composite risk factor that was created to reflect waitlist mortality and transplant survival. Thus, we believe that by using rigorous methods of identifying high-risk donors and high-risk recipients, we were able to improve on previous studies and provide data that facilitate

TABLE 5. Adjusted Cox regression of the number of extended donor criteria on one-year survival

\begin{tabular}{lll} 
Adjusted HR $(n=9658)$ & $95 \%$ CI & $P$ value \\
\hline
\end{tabular}

No. of donor criteria

$$
\begin{aligned}
& 0(\mathrm{n}=7203) \\
& 1(\mathrm{n}=3360) \\
& 2,3 \text {, or } 4(\mathrm{n}=432)
\end{aligned}
$$

Reference
1.35

$1.20-1.51<.001$

1.86

$1.49-2.32<.001$

The number of identified donor criteria met by donors represents the number of recipients who met 1 or 2 or more of the 4 donor factors used to define ECDs: age $\geq 65 \mathrm{y}$, a history of cigarette use for $\geq 20$ pack-y, diabetes, and African-American race. Because only 29 donors met 3 extended donor criteria, this group was included in a $\geq 2$ donor criteria. No donors met all 4 extended donor criteria. Recipients who received an SD organ were used as a reference. Cox regression model controlled for recipient variables, which included CMV mismatch, mechanical ventilation, BMI, creatinine, total bilirubin, ischemic time categorized by $<4, \geq 4$, and $<6, \geq 6$ and $<8$, and $\geq 8$, single lung transplant, sex, age, and diagnosis categorized by IPF, COPD, cystic fibrosis, pulmonary hypertension $\alpha 1$-antitrypsin deficiency, and other diagnoses. There were missing values in the covariates. The percentage of missing values for at least 1 covariate is $12 \%$. $H R$, Hazard ratio; $C I$, confidence interval. 


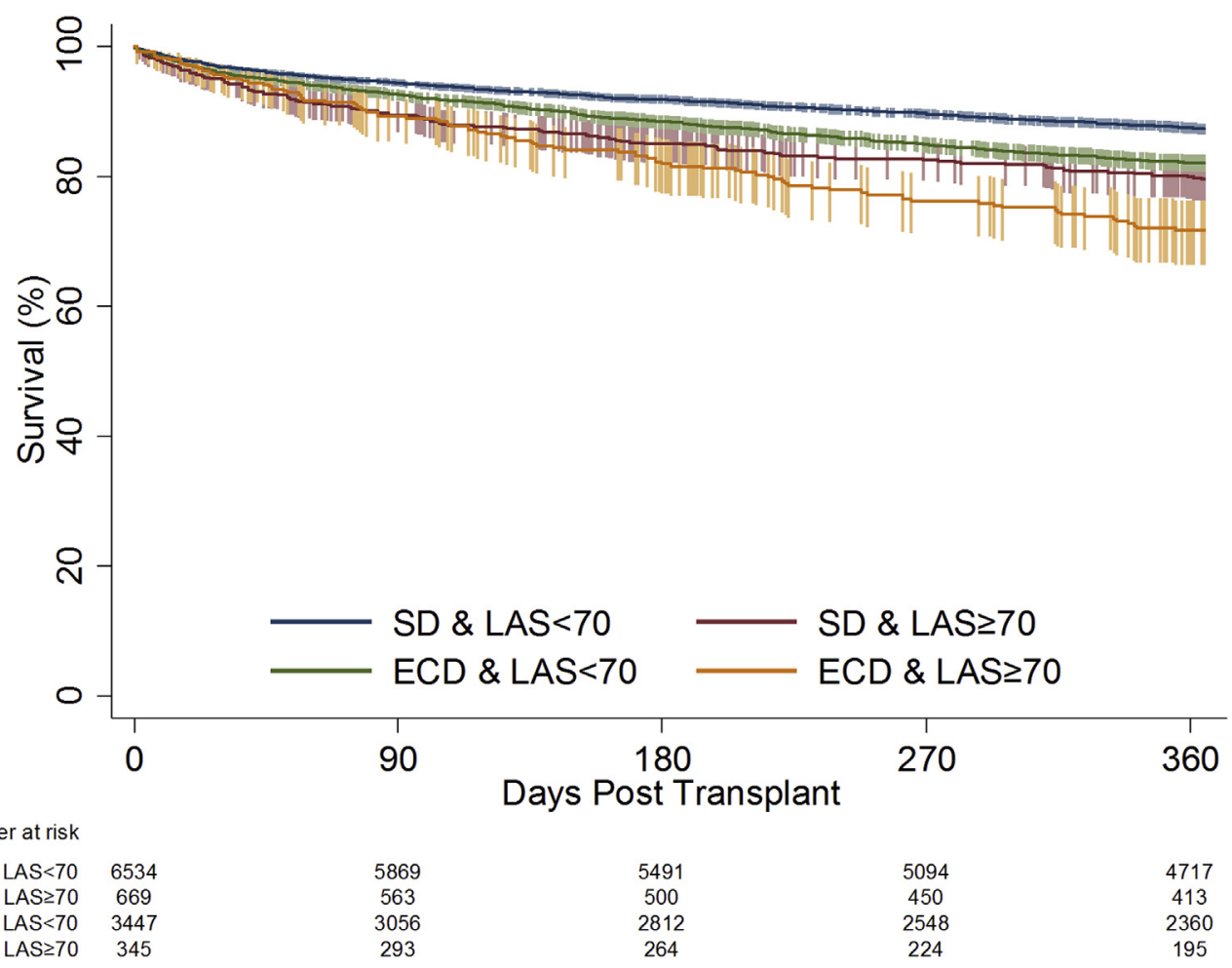

FIGURE 1. Kaplan-Meier transplant survival by donor quality and recipient severity. Error bars represent a $95 \%$ CI. ECD, Extended criteria donor; $L A S$, lung allocation score; $S D$, standard donor.

decision making in matching donor quality to recipient severity to optimize outcomes.

Our results on ECD characteristics are in agreement with data reported in the literature. Several investigators have shown that a history of cigarette smoking in the donor is associated with poor early outcomes, but it has no impact on midterm and long-term survival. ${ }^{10-12}$ Reyes and colleagues $^{6}$ recently analyzed 10,333 primary lung transplants using the OPTN/UNOS database from July 1999 to June 2008 and reported that donors with a smoking history

TABLE 6. Adjusted Cox regression of matching donor quality to recipient severity on one-year survival

\begin{tabular}{|c|c|c|c|}
\hline & $\begin{array}{c}\text { Adjusted } \\
\text { HR }(n=9659) \\
\end{array}$ & $95 \% \mathrm{CI}$ & $P$ value \\
\hline SD + recipient's LAS $<70$ & Reference & & \\
\hline ECD + recipient's LAS $<70$ & 1.42 & $1.27-1.60$ & $<.001$ \\
\hline $\mathrm{SD}+$ recipient's LAS $\geq 70$ & 1.37 & $1.10-1.71$ & .005 \\
\hline $\mathrm{ECD}+$ recipient's LAS $\geq 70$ & 1.81 & $1.40-2.33$ & $<.001$ \\
\hline
\end{tabular}

To assess the overall hazard of matching donor quality and recipient severity, a 4-category variable was created: SD and LAS $<70$, ECD and LAS $<70$, SD and LAS $\geq 70$, and ECD and LAS $\geq 70$ and used in a Cox regression while controlling for recipient variables, which included CMV mismatch, mechanical ventilation, creatinine, total bilirubin, ischemic time categorized by $<4, \geq 4$, and $<6, \geq 6$ and $<8$, and $\geq 8$, single lung transplant, age, and diagnosis categorized by IPF, COPD, cystic fibrosis, pulmonary hypertension $\alpha 1$-antitrypsin deficiency, and other diagnoses. Recipients with SD + LAS $<70$ were used as a reference. There were missing values in the covariates. The percentage of missing values for at least 1 covariate is $12 \%$. $H R$, Hazard ratio; $C I$, confidence interval; $S D$, standard donor; $L A S$, lung allocation score; $E C D$, extended criteria donor. more than 20 pack-years, with diabetes, or of AfricanAmerican race were associated with worse long-term survival. ${ }^{6}$ Our results also are in agreement with published data on the impact of donor age on patient survival. Previous studies have demonstrated that donor age has no impact on survival unless it was more than 65 years. ${ }^{6,13-15}$ Thus, we have defined ECDs to include any 1 of the following: smoking history 20 pack-years or more, donor age 65 years or more, African-American donors, and diabetic donors.

In addition to identifying donor characteristics that were independently associated with 1-year survival, we found that donors meeting an increasing number of extended donor criteria were associated with worse survival. This finding is discordant with published reports. In an analysis of ideal donor criteria in the OPTN/UNOS database, Reyes and colleagues ${ }^{6}$ found that increasing number of variances from ideal donor guidelines was not associated with worse survival. Moreno and colleagues ${ }^{9}$ showed that donor quality was not associated with outcomes when extended donors were defined with at least 2 variances from the ideal donor guidelines. ${ }^{10}$ However, both of these studies included random variances from the ideal donor criteria, of which many have been shown not to affect 1-year survival. ${ }^{6}$

\section{Study Limitations}

Our study is limited by the inherent limitations of a retrospective analysis of data captured within the OPTN/UNOS 
database. Some pertinent data, such as primary graft dysfunction, use of intraoperative cardiopulmonary bypass, and postoperative extracorporeal membrane oxygenation, are important prognostic indicators of survival but were not captured in the database. Furthermore, although being regularly evaluated for the integrity of all reported data to the registry, missing data and errors in data reporting always are potential problems. ${ }^{16}$ Notwithstanding these limitations, the current study provides a rigorous analysis of a large number of lung transplants in the modern era, and the results reported will be useful to the lung transplant community.

\section{CONCLUSIONS}

By using multivariable regression analysis of the OPTN/ UNOS dataset in the era of LAS, we identified 4 variables (age $\geq 65$ years, a smoking history of $\geq 20$ pack-years, diabetes, and African-American race) that were independent risk factors for mortality 1 year after lung transplantation and defined ECDs as donors with any of 1 these variables. Compared with donors who did not have any of these risk factors (SDs), ECD organs were associated with decreased 1-year survival when transplanted into both low-risk (LAS $<70$ ) and high-risk (LAS $\geq 70$ ) recipients. More important, ECD lungs were associated with the worst survival when transplanted into high-risk recipients. This study is the first large-scale investigation demonstrating that matching donor quality to recipient status is critical to achieve optimal outcomes in lung transplantation, which will guide lung transplant teams to make appropriate decisions in donor and recipient selection for their patients and their transplant centers.

\section{Webcast}

You can watch a Webcast of this AATS meeting presentation by going to: http://www.jtcvsonline.org/article/ S0022-5223(16)30278-1/addons.

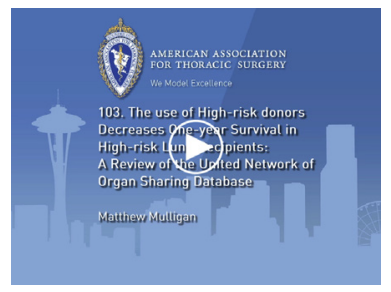

\section{Conflict of Interest Statement}

Authors have nothing to disclose with regard to commercial support.

\section{References}

1. Sundaresan S, Trachiotis GD, Aoe M, Patterson GA, Cooper JD. Donor lung procurement: assessment and operative technique. Ann Thorac Surg. 1993;56: 1409-13.
2. Gabbay E, Williams TJ, Griffiths AP, Macfarlane LM, Kotsimbos TC, Esmore DS, et al. Maximizing the utilization of donor organs offered for lung transplantation. Am J Respir Crit Care Med. 1999;160:265-71.

3. Orens JB, Boehler A, de Perrot M, Estenne M, Glanville AR, Keshavjee S, et al. A review of lung transplant donor acceptability criteria. J Heart Lung Transplant. 2003;22:1183-200.

4. Meers C, Van Raemdonck D, Verleden GM, Coosemans W, Decaluwe H, De Leyn P, et al. The number of lung transplants can be safely doubled using extended criteria donors; a single-center review. Transpl Int. 2010;23: 628-35.

5. Bhorade SM, Vigneswaran W, McCabe MA, Garrity ER. Liberalization of donot criteria may expand the donor pool without adverse consequence in lung transplantation. J Heart Lung Transplant. 2000;19:1199-204.

6. Reyes KG, Mason DP, Thuita L, Nowicki ER, Murthy SC, Pettersson GB, et al. Guidelines for donor lung selection: time for revision? Ann Thorac Surg. 2010; 89:1756-65

7. Liu V, Zamora MR, Dhillon GS, Weill D. Increasing lung allocation scores predict worsened survival among lung transplant recipients. Am J Transplant. 2010; 10:915-20.

8. Pierre AF, Sekine Y, Hutcheon MA, Waddell TK, Keshavjee SH. Marginal donor lungs: a reassessment. J Thorac Cardiovasc Surg. 2002;123:421-8.

9. Moreno P, Alvarez A, Santos F, Vaquero JM, Baamonde C, Redel J, et al. Extended recipients but not extended donors are associated with poor outcomes following lung transplantation. Eur J Cardiothorac Surg. 2014;45:1040-7.

10. Oto T, Griffiths AP, Levvey B, Pilcher DV, Whitford H, Kotsimbos TC, et al A donor history of smoking affects early but not late outcome in lung transplantation. Transplantation. 2004;78:599-606.

11. Diamond JM, Lee JC, Kawut SM, Shah RJ, Localio AR, Bellamy SL, et al. Clinical risk factors for primary graft dysfunction after lung transplantation. Am J Respir Crit Care Med. 2013;187:527-34.

12. Taghavi S, Jayarajan S, Komaroff E, Horai T, Brann S, Cordova F, et al. Doublelung transplantation can be safely performed using donors with heavy smoking history. Ann Thorac Surg. 2013;95:1912-8.

13. Dahlman S, Jeppsson A, Schersten H, Nilsson F. Expanding the donor pool: lung transplantation with donors 55 years and older. Transplant Proc. 2006;38:2691-3.

14. Shigemura N, Horai T, Bhama JK, D’Cunha J, Zaldonis D, Toyoda Y, et al. Lung transplantation with lungs from older donors: recipient and surgical factors affect outcomes. Transplantation. 2014;98:903-8.

15. Bittle GJ, Sanchez PG, Kon ZN, Claire Watkins A, Rajagopal K, Pierson RN III, et al. The use of lung donors older than 55 years: a review of the United Network of Organ Sharing database. J Heart Lung Transplant. 2013;32:760-8.

16. Leppke S, Leighton T, Zaun D, Chen SC, Skeans M, Israni AK, et al. Scientific Registry of Transplant Recipients: collecting, analyzing, and reporting data on transplantation in the United States. Transplant Rev (Orlando). 2013;27:50-6.

Key Words: lung transplantation, extended lung donor

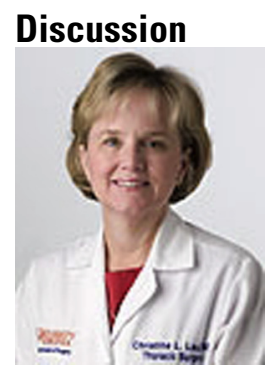

Dr C. Lau (Charlottesville, Va). I commend the authors for this outstanding study, and I appreciate the opportunity to review the slides and the article ahead of time. Matt, I think it is particularly impressive that you are a third-year medical student presenting at the American Association for Thoracic Surgery.

This is a large UNOS database study with results that, although not surprising, are very interesting. Essentially the use of high-risk recipients combined with high-risk donors decreases post-transplantation survival compared with low-risk donors combined with high-risk recipients, but there remains a substantial benefit to lung transplantation in this population compared with no lung transplantation. 
I have 2 questions. How have these results affected your practice? Because it is still significantly better than no transplantation, do you think these high-risk recipients should receive the first lung offer that comes to them or wait for a less-risky donor? It is likely with these higher LAS scores that they will get multiple chances. So to take a plug from Dr Cerfolio's discussion, if your mother was going to get a lung transplant, would you be happy to take the first donor if she was high risk and so was the donor?

Dr Mulligan (Baltimore, Md). This highlights a number of key points that we wanted to highlight through our discussion. First is how does this affect our practice? What we show is that matching donor quality and recipient severity is critical in lung transplantation. This has been intuitively done by surgeons, but now we are finally presenting the data behind this. This work will be important for surgeons to continue to triage donors to recipient risk factors to achieve optimal outcomes.

Next, you brought up the question: Should we use highrisk donors for high-risk recipients? Our data show that the use of high-risk donors in high-risk recipients is associated with a lower 1-year survival compared with lowrisk donors. However, these high-risk donors would improve the survival of the recipient compared with no transplant. So should high-risk donors be used for these patients? Ethically, these patients serve to benefit through a reduction in waitlist mortality with the use of high-risk donors. However, one must weigh the limitations of Center for Medicare and Medicaid Services and insurance companies potentially shutting down programs that don't meet certain survival criteria. Therefore, there is a balance that each program must make to weigh patient survival on the one hand with program survival on the other hand, perhaps highlighting the need for an ethical debate that should be discussed at a larger level.

Dr Lau. My second question, do you think from this article that perhaps a more national allocation system should be considered for high-risk recipients so that they have more access to the best donor? In the kidney transplant world, they have multiple donor-recipient switch transplants, albeit they are planned well ahead of time, but should we be more thoughtful in developing something similar in lung transplantation, or do you think this is not feasible?

Dr Mulligan. Clinically speaking, for optimal survival after listing, our results show that the high-risk recipients should undergo transplantation as soon as possible, preferably with low-risk donors. Thus, as you suggested, a revised policy is needed to allow these high-risk recipients to have access to a larger donor pool and the best-quality donors, whether that is a regional or a national level. However, when considering a regional level, there are other allocation factors that are important, such as ischemia time, cost, organizational limitations, and procurement team resources. Our results from our study may stimulate a discussion on a lung allocation policy.

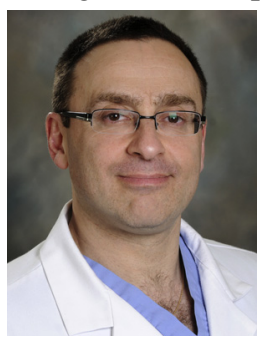

Dr A. Krupnick (St Louis, Mo). Did you do a subgroup analysis? Is it possible to see if there are 1 or 2 factors within the LAS score that outweigh everything else? For example, is the oxygen requirement more important than other factors? Are there certain factors within the LAS that we could break down and pick a better match combination? Are there certain factors where you should not accept the lung?

Dr Mulligan. That is a great question and something we show in our article that we were not able to present because of time. In the high-risk recipient group, recipients who had a LAS greater than or equal to 60 and who were aged more than 60 years did worse than those aged less than 60 years. So the difference that we found in those high-risk groups was actually due to older donors with high LAS scores.

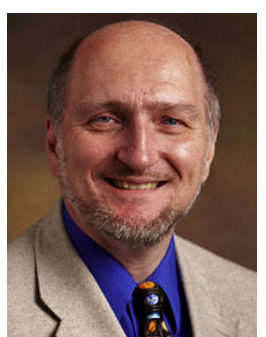

Dr G. Haasler (Milwaukee, Wis). Because the donor assessment often has been subjective, I wondered whether there is any move from the data that you have pooled to try to develop a scoring system for donors that might be used in conjunction with a LAS system to make a nice combination that might be a guide for people in smaller programs.

Dr Mulligan. That could be a great idea.

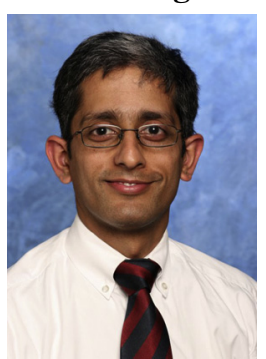

Dr V. Puri (St Louis, Mo). It probably was the case and you might not have had the time to show it, but were the patients who were high-risk recipients similar across baseline characteristics other than the LAS between the highrisk donors and the low-risk donors?

Dr Mulligan. Among the high-risk recipients, we found no differences between baseline characteristics of those who received organs from high-risk donors and those who received organs from low-risk donors. 
TABLE E1. Univariate Cox regressions of donor factors on one-year survival

\begin{tabular}{|c|c|c|c|c|}
\hline & Observations & HR & $95 \% \mathrm{CI}$ & $P$ value \\
\hline Age, y & 10,995 & & & \\
\hline$<55$ & & Reference & & \\
\hline $55-65$ & & 1.13 & $0.96-1.34$ & .140 \\
\hline$\geq 65$ & & 2.16 & 1.53-3.05 & $<.001$ \\
\hline $\mathrm{Po}_{2} \leq 300$ & 10,901 & 0.97 & $0.86-1.08$ & .534 \\
\hline $\begin{array}{l}\text { History of smoking } \\
\geq 20 \text { pack-y }\end{array}$ & 10,899 & 1.26 & $1.10-1.46$ & .001 \\
\hline Abnormal chest $\mathrm{x}$-ray & 10,955 & 0.96 & $0.87-1.06$ & .439 \\
\hline $\begin{array}{l}\text { Purulent secretions } \\
\text { on bronchoscopy }\end{array}$ & 9914 & 1.02 & $0.87-1.19$ & .824 \\
\hline Diabetes & 10,963 & 1.36 & 1.14-1.63 & .001 \\
\hline Female & 10,995 & 1.05 & $0.95-1.16$ & .347 \\
\hline Race & 10,995 & & & \\
\hline Caucasian & & Reference & & \\
\hline African-American & & 1.43 & 1.27-1.61 & $<.001$ \\
\hline Other & & 1.13 & $0.99-1.29$ & .062 \\
\hline Mechanism of death & 10,994 & & & \\
\hline Stroke & & Reference & & \\
\hline Blunt trauma & & 0.90 & $0.79-1.02$ & .095 \\
\hline Gunshot & & 0.95 & 0.83-1.09 & .468 \\
\hline Asphyxiation & & 0.73 & $0.51-1.05$ & .089 \\
\hline Other & & 0.88 & $0.75-1.03$ & .116 \\
\hline BMI & 10,995 & 1.00 & $0.99-1.01$ & .848 \\
\hline $\begin{array}{l}\text { Coronary artery } \\
\text { disease }\end{array}$ & 10,991 & 1.24 & $1.00-1.54$ & .048 \\
\hline Hypertension & 10,994 & 1.22 & 1.09-1.37 & .001 \\
\hline $\mathrm{ABO}$ group & 10,995 & & & \\
\hline A & & Reference & & \\
\hline $\mathrm{AB}$ & & 1.00 & $0.70-1.42$ & .995 \\
\hline B & & 1.10 & $0.93-1.30$ & .271 \\
\hline $\mathrm{O}$ & & 1.03 & $0.93-1.15$ & .584 \\
\hline
\end{tabular}

Each donor factor was run on a separate univariate Cox hazard regression on 1-y survival. The bolded variables (age $\geq 65 \mathrm{y}$, smoking history $\geq 20$ pack-y, diabetes, coronary artery disease, and hypertension) were significantly associated with reductions in 1-y transplant survival and were placed in a stepwise regression. $\mathrm{HR}$, Hazard ratio; $\mathrm{CI}$, confidence interval; $\mathrm{PO}_{2}$, oxygen tension; $\mathrm{BMI}$, body mass index.

TABLE E2. Adjusted Cox stepwise regressions of identified donor factors on one-year survival

\begin{tabular}{|c|c|c|c|c|c|c|c|c|c|}
\hline & \multicolumn{3}{|c|}{ Model 1 (n = 9561) } & \multicolumn{3}{|c|}{ Model $2(n=9561)$} & \multicolumn{3}{|c|}{ Model $3(n=9563)$} \\
\hline & HR & $95 \%$ CI & $P$ value & HR & $95 \%$ CI & $P$ value & HR & $95 \%$ CI & $P$ value \\
\hline \multicolumn{10}{|l|}{ Donor factors } \\
\hline Age $\geq 65$ y & 2.11 & $1.47-3.04$ & .000 & 2.14 & $1.50-3.07$ & .000 & 2.14 & $1.50-3.07$ & .043 \\
\hline History of smoking $\geq 20$ pack-y & 1.28 & $1.10-1.50$ & .002 & 1.29 & $1.10-1.50$ & .001 & 1.29 & $1.11-1.51$ & .001 \\
\hline Diabetes & 1.27 & $1.03-1.55$ & .025 & 1.29 & $1.06-1.56$ & .010 & 1.29 & $1.07-1.57$ & .009 \\
\hline African-American race & 1.34 & $1.18-1.52$ & .000 & 1.34 & $1.18-1.52$ & .000 & 1.34 & $1.18-1.52$ & .000 \\
\hline Coronary artery disease & 1.08 & $0.84-1.39$ & .539 & 1.09 & $0.85-1.40$ & .504 & & & \\
\hline Hypertension & 1.03 & $0.90-1.18$ & .658 & & & & & & \\
\hline
\end{tabular}

A stepwise regression of donor factors that were significantly associated with reduced 1-y survival in univariate analysis were run in a stepwise regression while controlling for recipient variables, including CMV mismatch, mechanical ventilation, BMI, creatinine, total bilirubin, ischemic time categorized by $<4, \geq 4$, and $<6, \geq 6$ and $<8$, and $\geq 8$, single lung transplant, sex, age, and diagnosis categorized by IPF, COPD, cystic fibrosis, pulmonary hypertension $\alpha 1$-antitrypsin deficiency, and other diagnoses. Donor factors were removed from the model sequentially, starting with the largest $P$ value, until all $P$ values were less than .05 . $H R$, Hazard ratio; $C I$, confidence interval. 
TABLE E3. Crude and adjusted Cox regressions of donor factors on one-year survival

\begin{tabular}{|c|c|c|c|c|c|c|}
\hline & Crude HR $(n=10,888)$ & $\mathbf{9 5} \% \mathbf{C I}$ & $P$ value & Adjusted HR $(n=9563)$ & $\mathbf{9 5} \%$ CI & $P$ value \\
\hline \multicolumn{7}{|l|}{ Donor factor model } \\
\hline Age $\geq 65$ y & 2.17 & $1.52-3.08$ & $<.001$ & 2.14 & $1.50-3.07$ & $<.001$ \\
\hline History smoking $\geq 20$ pack-y & 1.30 & $1.13-1.50$ & $<.001$ & 1.29 & $1.11-1.51$ & .001 \\
\hline Diabetes & 1.31 & $1.10-1.57$ & .003 & 1.29 & $1.07-1.57$ & .009 \\
\hline African-American & 1.40 & $1.25-1.57$ & $<.001$ & 1.34 & $1.18-1.52$ & $<.001$ \\
\hline
\end{tabular}

In the donor factor model, a multivariable stepwise regression model was used to identify significant donor factors on 1-y survival. The adjusted Cox regression controlled for recipient variables, which included CMV mismatch, mechanical ventilation, BMI, creatinine, total bilirubin, ischemic time categorized by $<4, \geq 4$, and $<6, \geq 6$ and $<8$, and $\geq 8$, single lung transplant, sex, age, and diagnosis categorized by IPF, COPD, cystic fibrosis, pulmonary hypertension $\alpha 1$-antitrypsin deficiency, and other diagnoses. There were missing values in the covariates and in the individual donor factors. The percentage of missing values for at least 1 variable is $13 \%$. $H R$, Hazard ratio; $C I$, confidence interval.

TABLE E4. Crude and adjusted Cox regressions of extended criteria donors and the number of donor criteria on one-year survival

\begin{tabular}{|c|c|c|c|c|c|c|}
\hline & Crude HR $(n=10,995)$ & $95 \%$ CI & $P$ value & Adjusted HR $(n=9658)$ & $95 \%$ CI & $P$ value \\
\hline ECDs & 1.48 & $1.31-1.60$ & $<.001$ & 1.41 & $1.26-1.56$ & $<.001$ \\
\hline \multicolumn{7}{|c|}{ No. of donor criteria } \\
\hline 0 & Reference & & & Reference & & \\
\hline 1 & 1.39 & $1.25-1.54$ & $<.001$ & 1.35 & $1.20-1.51$ & $<.001$ \\
\hline$\geq 2$ & 1.91 & $1.55-2.35$ & $<.001$ & 1.86 & $1.49-2.32$ & $<.001$ \\
\hline
\end{tabular}

ECDs were identified as having at least 1 of the following: age $>65 \mathrm{y}$, history of smoking $\geq 20$ pack-y, diabetes, or African-American race. The number of identified donor criteria met by donors represents the number of donors who met 1 or 3 or more of the 4 donor factors used to define ECDs. Because only 29 donors met 3 extended donor criteria, this group was included in a $\geq 2$ donor criteria. No donors met all 4 extended donor criteria. Recipients who received an SD lung were used as a reference. The adjusted Cox regressions controlled for recipient factors, which included CMV mismatch, mechanical ventilation, BMI, creatinine, total bilirubin, ischemic time categorized by $<4, \geq 4$, and $<6, \geq 6$ and $<8$, and $\geq 8$, single lung transplant, sex, age, and diagnosis categorized by IPF, COPD, cystic fibrosis, pulmonary hypertension $\alpha 1$-antitrypsin deficiency, and other diagnoses. There were missing values in the covariates. The percentage of missing values for at least 1 covariate is $12 \%$. $H R$, Hazard ratio; $C I$, confidence interval; $E C D$, extended criteria donor.

TABLE E5. Crude and adjusted Cox regressions of matching donor quality and recipient severity on one-year survival

\begin{tabular}{|c|c|c|c|c|c|c|}
\hline & Crude HR $(n=10,995)$ & $95 \%$ CI & $P$ value & Adjusted HR $(n=9659)$ & $95 \%$ CI & $P$ value \\
\hline $\mathrm{SD}+$ recipient's LAS $<65$ & Reference & & & Reference & & \\
\hline ECD + recipient's LAS $<65$ & 1.46 & $1.31-1.62$ & $<.001$ & 1.42 & $1.27-1.60$ & $<.001$ \\
\hline $\mathrm{SD}+$ recipient's LAS $\geq 65$ & 1.72 & $1.43-2.08$ & $<.001$ & 1.37 & $1.10-1.71$ & .005 \\
\hline $\mathrm{ECD}+$ recipient's LAS $\geq 65$ & 2.39 & $1.92-2.97$ & $<.001$ & 1.81 & $1.40-2.33$ & $<.001$ \\
\hline
\end{tabular}

To assess the overall hazard of matching donor quality and recipient severity, a 4-category variable was created and used in Cox regression analysis: SDs and LAS $<65$, ECDs and LAS $<65$, SDs and LAS $\geq 65$, and ECDs and LAS $\geq 65$. The adjusted Cox regression controlled for recipient variables, which included CMV mismatch, mechanical ventilation, creatinine, total bilirubin, ischemic time categorized by $<4, \geq 4$, and $<6, \geq 6$ and $<8$, and $\geq 8$, single lung transplant, age, and diagnosis categorized by IPF, COPD, cystic fibrosis, pulmonary hypertension $\alpha 1$-antitrypsin deficiency, and other diagnoses. There were missing values in the covariates. The percentage of missing values for at least 1 covariate is $12 \%$. HR, Hazard ratio; $C I$, confidence interval; $S D$, standard donor; $L A S$, lung allocation score; $E C D$, extended criteria donor. 